\title{
Introduction to Disability, Rights and Law Reform in Australia: Pushing Beyond Legal Futures
}

\author{
Fleur Beaupert, Linda Steele and Piers Gooding
}

The United Nations Convention on the Rights of Persons with Disabilities ${ }^{1}$ (CRPD), which entered into force in May 2008, has been hailed by disability rights scholars and activists as effecting monumental shifts in the status of people with disability ${ }^{2}$ under international human rights law. A key reason is that the CRPD embodies a 'social model' understanding of disability, focused on systemic factors and barriers to equality, that is in contrast to the earlier reductive, individualised 'medical models' of disability apparent in international human rights law that legitimated differential treatment of people with disability on the basis of their purported internal, pathological deficits. ${ }^{3}$ Some have even claimed that the CRPD moves beyond a social model, to introduce a 'human rights model' of disability. Theresia Degener, the current Chair of the United Nations Committee on the Rights of Persons with Disabilities (the UN Committee), argues that although the social model holds strong explanatory power in identifying the formation of disability, it does not affirm the inherent human dignity of people with disability and attribute them with the capacity to hold human rights regardless of impairment. ${ }^{4}$ According to Degener, the human rights model creates a broader framework for achieving social justice, offering not just an explanation, but a prescription for change. ${ }^{5}$ Perhaps time will tell whether this is true or not, but it is certainly the case that the CRPD is among the longest and most detailed of all UN human rights treaties, elucidating rights in the disability context in a range of areas of life, including rights to work, education, health services, transportation, access to justice, and accessibility of the physical and social environment. ${ }^{6}$

1 Convention on the Rights of Persons with Disabilities, opened for signature 30 March 2007, 2515 UNTS 3 (entered into force 3 May 2008) (CRPD). The CRPD was adopted by the United Nations General Assembly on 13 December 2006.

2 For a critical engagement with the definition of disability in the CRPD and its relationship to the mental health context, see Brendan Kelly, Dignity, Mental Health and Human Rights: Coercion and the Law (Ashgate, 2015) 94-95.

3 Maya Sabatello and Marianne Schulze, 'A Short History of the International Disability Rights Movement' in Maya Sabatello and Marianne Schulze (eds), Human Rights and Disability Advocacy (University of Pennsylvania Press, 2014) 1, 15-20.

4 Theresia Degener, 'A New Human Rights Model of Disability' in Valentina Della Fina, Rachele Cera and Giuseppe Palmisano (eds), The United Nations Convention on the Rights of Persons with Disabilities (Springer, 2018) 41. Ibid.

6 CRPD Arts 9, 13, 24, 25, 28. 
At the heart of the CRPD is a claim for equality. The mandate of the negotiators was not to introduce new rights but rather to apply existing rights so as to redress the failure of existing human rights instruments to promote the rights of people with disability. ${ }^{7}$ The CRPD signals a movement away from:

[V]iewing persons with disabilities as 'objects' of charity, medical treatment and social protection towards viewing persons with disabilities as 'subjects' with rights, who are capable of claiming those rights and making decisions for their lives based on their free and informed consent as well as being active members of society. ${ }^{8}$

Facilitating this transformation required the drafters to reformulate and expand existing statements of rights through both individual articles and their interconnection. ${ }^{9}$ For example, the inclusion of 'accessibility' as a guiding principle in Art 3, and as a right in Art 9 denoting obligations of states parties' aimed at ensuring that people with disability can live independently and fully participate in society, represents the first time this concept has been mentioned in an international treaty. ${ }^{10}$ Overall, the provisions of the CRPD engender a cultural shift which challenges the way in which human rights have historically been 'premised upon the differential and discriminatory treatment' of people considered to lack mental capacity. ${ }^{11}$ The CRPD can thus be viewed as articulating existing human rights in a manner sensitive to the experiences of marginalisation and oppression of people with disability and to the kinds of life experiences they commonly encounter. The negotiations leading to the Convention's adoption and the Working Group convened to draft the text involved significant representation by disabled people's organisations. ${ }^{12}$

Within Australia, the CRPD has the potential to profoundly change how law conceptualises and responds to disability. The decade since the CRPD entered into force has witnessed a variety of law and policy reform activity in the disability context, in response to a growing awareness of

$7 \quad$ Rosemary Kayess and Phillip French, 'Out of Darkness into Light? Introducing the Convention on the Rights of Persons with Disabilities' (2008) 8 Human Rights Law Review 1, 20.

8 United Nations Enable-Secretariat for the CRPD, Paradigm Shift <http://www. un.org/esa/socdev/enable/convinfopara.htm>.

$9 \quad$ See Kayess and French, above n 7, 32-33.

10 United Nations Enable-Secretariat for the CRPD, above n 8.

11 See Linda Steele, 'Court Authorised Sterilisation and Human Rights: Inequality, Discrimination and Violence against Women and Girls with Disability (2016) 39(3) University of New South Wales Law Journal 1002, 1014-1016. For an explanation of the concept of 'mental capacity' and its relationship to 'legal capacity' within the international human rights framework, see Committee on the Rights of Persons with Disabilities, General Comment No 1: Article 12: Equal Recognition before the Law, 11th sess, UN Doc CRPD/C/GC/1 (11 April 2014) [13]-[15] (General Comment No 1).

12 The list of non-governmental organisations representing disabled people that participated in the CRPD Working Group can be found on the website of the United Nations Enable-Secretariat for the CRPD, Working Group on a Convention $<$ http://www.un.org/esa/socdev/enable/rights/ahcwg.htm\#membership>. 
barriers to equal justice and other legal issues confronting people with disability. In November 2015, a Senate Committee inquiry reported that people with disability experience widespread violence, abuse and neglect, including being subjected to forcible actions that would constitute violence in any other context on the pretext of providing 'therapeutic treatment', ${ }^{13}$ a practice which Linda Steele has termed 'disability-specific lawful violence'. ${ }^{14}$ A year later, another Senate Committee inquiry recommended changes to laws, policies and systems nationwide in response to evidence about the practice of indefinite detention of people with cognitive disability and mental health issues in institutions such as prisons and psychiatric facilities. ${ }^{15}$ The terms of reference for both of these inquiries included consideration of compliance with Australia's international human rights obligations. Since ratification of the CRPD, most States and Territories have undertaken reviews of their civil mental health laws, ${ }^{16}$ and a number of jurisdictions have completed or commenced reviews of their guardianship laws. ${ }^{17}$ The resulting inquiries, proposals

13 Senate Community Affairs References Committee, Parliament of Australia, Violence, Abuse and Neglect against People with Disability in Institutional and Residential Settings, including the Gender and Age Related Dimensions, and the Particular Situation of Aboriginal and Torres Strait Islander People with Disability, and Culturally and Linguistically Diverse People with Disability (2015) xxvi.

14 Linda Steele, 'Disability, Abnormality and Criminal Law: Sterilisation as Lawful and Good Violence' (2014) 23(3) Griffith Law Review 467; Linda Steele, Submission to Senate Community Affairs References Committee, Parliament of Australia, Inquiry into Violence, Abuse and Neglect against People with Disability in Institutional and Residential Settings, including the Gender and Age Related Dimensions, and the Particular Situation of Aboriginal and Torres Strait Islander People with Disability, and Culturally and Linguistically Diverse People with Disability, 26 June 2015 <http://www.academia.edu/14567241/ Submission_to_the_Senate_Community_Affairs_References_Committee_ Inquiry_into_violence_abuse_and_neglect_against_people_with_disability_in_ institutional_and_residential_settings_2015_>.

15 Senate Community Affairs References Committee, Parliament of Australia, Indefinite Detention of People with Cognitive and Psychiatric Impairment in Australia (2016).

16 ACT Law Reform Advisory Council, Guardianship Report (2016); NSW Health, Review of the NSW Mental Health Act 2007, Summary of Consultation Feedback and Advice (2013); Queensland Health, Review of the Mental Health Act 2000, Discussion Paper (2014); SA Health, The Review of the Mental Health Act 2009: A Report by the Chief Psychiatrist of South Australia (2014); Tasmanian Department of Health and Human Services, Review of the Mental Health Act 1996, Issues Paper (2007); Victorian Department of Health, A New Mental Health Act for Victoria: Summary of Proposed Reforms (2012); Western Australian Mental Health Commission, Summary Overview of the Draft Mental Health Bill 2011 (2011). The last review of the Mental Health and Related Services Act (NT) was completed in 2000: Centre for International Economics, NCP Review of the Northern Territory Mental Health and Related Services Act, Final Report (2000).

17 Victorian Law Reform Commission, Guardianship, Final Report 24 (2012); Queensland Law Reform Commission, A Review of Queensland's Guardianship Laws, Report 67 (2010); ACT Law Reform Advisory Council, above n 16. The Guardianship of Adults Act (NT) commenced operation on 28 July 2016, and a 
and measures have generally been intended to give effect to the CRPD's principles. $^{18}$

The impact of the CRPD in Australia is, however, somewhat paradoxical. In certain respects, Australia has led international efforts at domestic application of this international treaty. One such example is the much feted National Disability Insurance Scheme (NDIS). The National Disability Insurance Scheme Act 2013 (Cth), which is the legislation that enacts and regulates the scheme, explicitly refers to compliance with the CRPD as its very first objective. ${ }^{19}$ In the course of developing the NDIS, the government signalled increased funding for disability services when many in the developed West are doing the opposite. Another example is the Australian Law Reform Commission (ALRC) report on Equality, Capacity and Disability in Commonwealth Laws, which brings together a wealth of Australian-led and international activity on the CRPD, and is arguably the most comprehensive attempt by any national law reform agency to tackle the challenging implications of the call for equal recognition before the law for people with disability. Australia also contributed key players to the negotiation and implementation of the CRPD, including figures such as Ron McCallum, Rosemary Kayess, Graeme Innes, Heidi Forrest, Frank Hall-Bentick, Phillip French and the national cross-disability and advocacy organisation People with Disability Australia. ${ }^{20}$

Yet, in other ways, Australia has struggled to translate the 'majestic generalities' of international human rights law into national laws, policies and service delivery systems in ways that will impact the everyday lives of people with disability. While the NDIS has launched the issue of disability into the public sphere, inviting shifts in models of support that arguably reflect aspects of a social model of disability, there are still many concerns about the extent to which it provides opportunities for systemic change. The scheme currently has a narrow definition of disability support and does not extend to funding systemic advocacy for rights-based disability organisations. ${ }^{21}$ Concerns have been expressed about the ability of the NDIS to meet the needs of some of the most marginalised people with

review of the Guardianship Act 1987 (NSW) is currently underway: NSW Law Reform Commission, Review of the Guardianship Act 1987 (11 April 2017) <http:// www.lawreform.justice.nsw.gov.au/Pages/lrc/lrc_current_projects/Guardianship/ Guardianship.aspx>.

18 However, the Queensland review of civil mental health laws did not appear to consider the CRPD at all, according to publicly available documents recording the review process and outcomes: Queensland Health, above n 16.

19 National Disability Insurance Scheme Act 2013 (Cth) s 3(1)(a).

20 For a fuller account of the Australian delegation to the CRPD negotiations, see Heidi Forrest and Phillip French, 'Voices Down Under: An Australian Perspective' in Maya Sabatello and Marianne Schulze (eds), Human Rights and Disability Advocacy (University of Pennsylvania Press, 2013) 188.

21 Kelsey Munro, 'NSW Support Services Facing Funding Cut in NDIS Transition', The Sydney Morning Herald (online), 5 March 2017 <http://www.smh.com.au/nsw/ nsw-support-services-facing-funding-cut-in-ndis-transition-20170302-guppo8. html>. 
disability, such as those who are in prison, ${ }^{22}$ and about the privatisation of associated disability support services, notably the heightened risk of exploitation in the pursuit of profits. ${ }^{23}$ It seems fair to say that little of the policy activity surrounding the NDIS has been concerned with the CRPD. This is perhaps understandable given that the NDIS is an actuarial scheme - but the absence of rights discourse may point to a broader issue to do with human rights in Australia. Australia is in the rather unique position whereby international treaty obligations do not take binding effect unless and until they have been specifically adopted into domestic law through legislation. As a result, many of the rights set out in the CRPD, and its 'parent' treaties, the International Covenant on Civil and Political Rights ${ }^{24}$ (ICCPR) and the International Covenant on Economic, Social and Cultural Rights, ${ }^{25}$ do not have direct effect in Australia. Linda Steele has discussed how this lack of binding force has recently been relied upon as a basis on which not to reform laws regulating the sterilisation of women and girls to better realise the rights in the CRPD. ${ }^{26}$

Some compliance mechanisms do exist. Australia has acceded to the Optional Protocol to the International Covenant on Civil and Political Rights, ${ }^{27}$ a separate treaty which establishes a complaint mechanism allowing individuals who have exhausted their domestic remedies without success to allege violations of their ICCPR rights. Australia also acceded to the Optional Protocol to the Convention on the Rights of Persons with Disabilities ${ }^{28}$ which came into force for Australia on 20 September 2009. The Optional Protocol recognises the competence of the UN Committee to receive and consider communications from or on behalf of individuals or groups who claim CRPD rights violation and have exhausted all domestic remedies. The recent UN Committee finding on the case of Western Australian man, Mr Marlon Noble, is one such example. ${ }^{29} \mathrm{Mr}$

22 Jesse Young and Stuart Kinner, 'Prisoners are Excluded from the NDIS - Here's Why it Matters', The Conversation (online), 19 January $2017<$ https://theconversation.com/prisoners-are-excluded-from-the-ndis-heres-why-it-matters-73912>.

23 Jennifer Macey, 'NDIS: Warnings Privatising Scheme Could Lead to Dodgy Operators More Interested in Profit Than People', $A B C$ News (online), 1 May 2015 <http://www.abc.net.au/news/2015-03-01/ warnings-ndis-privatisation-could-lead-to-dodgy-operators/6271502>.

24 International Covenant on Civil and Political Rights, opened for signature 19 December 1966, 999 UNTS 172 (entered into force 23 March 1976) (ICCPR).

25 International Covenant on Economic, Social and Cultural Rights, opened for signature 16 December 1966, 993 UNTS 3 (entered into force 3 January 1976).

26 For example, Steele, 'Court-Authorised Sterilisation and Human Rights', above n 11, 1026.

27 Optional Protocol to the International Covenant on Civil and Political Rights, opened for signature 19 December 1966, 999 UNTS 302 (entered into force 23 March 1976).

28 Optional Protocol to the Convention on the Rights of Persons with Disabilities, opened for signature 13 December 2006, 2518 UNTS 283 (entered into force 3 May 2008).

29 Committee on the Rights of Persons with Disabilities, Views: Communication No 7/2012, 16th sess, UN Doc CRPD/C/16/D/7/2012 (2 September 2016) 15 [8.4]. 
Noble, who was indefinitely detained for over 10 years following a finding that he was unfit to stand trial, was found to have been denied his general right to equality and non-discrimination (Art 5); and his specific rights to equal recognition before the law (Art 12); access to justice (Art 13); liberty, including freedom from deprivations of liberty on the basis of disability (Art 14); and freedom from cruel, inhuman and degrading treatment (Art 15). It is interesting to note that these violations occurred under Western Australian law, and that the Federal Government, to which the UN Committee directed its statement, does not have a clear enforcement mechanism to change the relevant State laws. ${ }^{30}$ Once again, the absence of strong enforcement mechanisms means that the 'expressive, educational and proactive' role of the CRPD, to use Oliver Lewis' terms, ${ }^{31}$ will be particularly important in Australia.

$\mathrm{Mr}$ Noble is one of a number of recent high-profile cases that have drawn public attention to the plight of Indigenous people with disability, much of it focused on Indigenous people with cognitive and psychosocial disabilities who become enmeshed in the criminal justice system. The unique disadvantage facing Indigenous people with disability is bound up in experiences of institutional racism and the ongoing impact of colonisation. This broader disadvantage is evidenced by recent research by Eileen Baldry and colleagues on the way in which legal systems and support services respond to the needs of Indigenous people with disability in criminal justice. ${ }^{32}$ This research demonstrated the disproportionate extent to which Indigenous people with cognitive and psychosocial disabilities are 'managed' by the criminal justice system from an early age, in the absence of coherent, holistic community support frameworks. ${ }^{33}$ The project's recommendations about responses that can assist in ensuring that Indigenous people with disability are supported to live in their own communities and avoid predictable pathways into the criminal justice system include resourcing Indigenous-led knowledge and solutions in line

This complaint mechanism has been utilised by a number of Australians with disability, including Michael Lockrey and Gemma Beasley in relation to participation in the jury selection process and jury duty by deaf people: Committee on the Rights of Persons with Disabilities, Views: Communication No 11/2013, 15th sess, UN Doc CRPD/C/15/11/2013 (1 April 2016); Committee on the Rights of Persons with Disabilities, Views: Communication No 13/2013, 15th sess, UN Doc CRPD/C/15/D/13/2013 (1 April 2016).

30 For a discussion of the complexities of law reform within Australia's federal system, see Marisa Payne, 'Law Reform and the Legislature' in Brian Opeskin and David Weisbrot (eds), The Promise of Law Reform (Federation Press, 2015) 302, 302-306.

31 Oliver Lewis, 'The Expressive, Educational and Proactive Roles of Human Rights' in Bernadette McSherry and Penelope Weller (eds), Rethinking Rights-Based Mental Health Laws (Hart, 2010) 96.

32 Eileen Baldry, Ruth McCausland, Leanne Dowse and Elizabeth McEntyre, $A$ Predictable and Preventable Path: Aboriginal People with Mental and Cognitive Disabilities in the Criminal Justice System (UNSW, 2015) $97<$ https://www. mhdcd.unsw.edu.au>. 
with the principle of self-determination. ${ }^{34}$ The First Peoples Disability Network, a key contributor to policy debates and initiatives relating to the human rights of First Peoples with disability, has highlighted the need for culturally appropriate research methodologies and delivery of services. ${ }^{35}$

This special issue of Law in Context provides a timely forum for critical analysis and reflection on the impact on Australian law of advancements in international human rights law related to disability. Disability affects a substantial proportion of the Australian population, both Indigenous and non-Indigenous. According to the Australian Bureau of Statistics (ABS), over four million (almost one in five) people in Australia have some form of disability, with almost 80 per cent of those people reporting a physical condition and the remainder reporting 'mental and behavioural disorders'. ${ }^{36}$ The issues addressed in the articles in this special issue concern ongoing barriers people with disability face in participating as equal members of society in political, public and cultural life, as evidenced by the following findings deriving from ABS statistics:

- 53 per cent of people with a disability aged 15-64 are currently employed, compared with 83 per cent of people without a disability;

- 41 per cent of people with a disability aged 15-64 have completed Year 12, compared with 63 per cent of those without a disability;

- people with disability are approximately twice as likely to be in the bottom 40 per cent of gross household incomes; ${ }^{37}$ and

- people with disability experience all forms of violence at higher rates than other people. ${ }^{38}$

Historically, some such disparities have been attributed to deficits and pathologies internal to people with disability - or considered merely a matter of the misfortune sometimes assumed to accompany disability. The CRPD instead foregrounds the disabling impact of external attitudinal and environmental barriers that hinder the full and effective participation of people with disability in society.

There is a growing body of literature about the CRPD as a body of international human rights law, including discussion about its interface

$34 \quad$ Ibid 161.

35 For example, First People's Disability Network Australia, Ten-Point Plan for the Implementation of the NDIS in Aboriginal and Torres Strait Islander Communities (2 April 2016) <http://fpdn.org.au/ ten-point-plan-for-the-implementation-of-the-ndis-in-aboriginal-communities/>.

36 Australian Bureau of Statistics, 4430.0-Disability, Ageing and Carers, Australia: Summary of Findings, 2015 (18 October 2016) <http://www.abs.gov.au/ausstats/ abs@.nsf/mf/4430.0>.

37 Ibid.

38 Lauren Krnjacki, Eric Emerson, Gwynnyth Llewellyn and Anne M Kavanagh, 'Prevalence and Risk of Violence against People with and without Disabilities: Findings from an Australian Population-Based Study' (2016) 40(1) Australian and New Zealand Journal of Public Health 16. 
with Australian law. ${ }^{39}$ However, much existing commentary on implementing the CRPD in Australia concerns civil laws, in particular mental health and guardianship laws, and their compliance with Art 12. Article 12, entitled 'Equal recognition before the law', articulates the right to legal capacity on an equal basis, as a subsidiary to the right to equal recognition before the law. This 'parent' right appears in the Universal Declaration of Human Rights ${ }^{40}$ and the ICCPR. ${ }^{41}$ The right to legal capacity on an equal basis with others was first advanced in 1979 in Art 15(2)-(3) of the Convention on the Elimination of All Forms of Discrimination against Women. ${ }^{42}$ These antecedents are important because, as Piers Gooding has written, "Article 12 of the [CRPD] does not introduce a "new model" of legal capacity ... Instead, while the scope and content of the right to legal capacity in Article 12 is not new, its application is unique - restated as it is for the context of disability. ${ }^{33}$ While a persistent focus on Art 12 is understandable in light of its foundational mandate, this provision has overwhelmingly been reduced to debate about the relative legal positions of substitute decision-making and 'supported decision-making' according to international human rights law, and associated implementation issues. ${ }^{44}$ Supported decision-making encompasses a range of processes

39 For example, Aminath Didi, Karen Soldatic, Carolyn Frohmader and Leanne Dowse, 'Violence against Women with Disabilities: Is Australia Meeting its Human Rights Obligations?' (2016) 22(1) Australian Journal of Human Rights 159; Bernadette McSherry and Juan José Tellez, 'Current Challenges for the Regulation of Chemical Restraint in Health Care Settings' (2016) 24 Journal of Law and Medicine 15; Terry Carney, 'Supported Decision-Making for People with Cognitive Impairments: An Australian Perspective?' (2015) 4(1) Laws 37; Michelle Browning, Christine Bigby and Jacinta Douglas, 'Supported Decision Making: Understanding How Its Conceptual Link to Legal Capacity is Influencing the Development of Practice' (2014) 1(1) Research and Practice in Intellectual and Developmental Disabilities 34; Phillip French and Rosemary Kayess, 'Deadly Currents Beneath Calm Waters: Persons with Disability and the Right to Life in Australia' in Luke Clements and Janet Read (eds), Disabled People and the Right to Life: The Protection and Violation of Disabled People's Most Basic Human Rights (Routledge, 2008) 57-84; John Chesterman, 'The Future of Adult Guardianship in Federal Australia' (2013) 66(1) Australian Social Work 26.

40 Universal Declaration of Human Rights, GA Res 217A (III), UN GAOR, 3rd sess, 183rd plen mtg, UN Doc A/810 (10 December 1948) Art 6.

41 ICCPR Art 16.

42 Convention on the Elimination of All Forms of Discrimination against Women, opened for signature 18 December 1979, 1249 UNTS 13 (entered into force 3 September 1981).

43 Piers Gooding, 'Navigating the 'Flashing Amber Lights' of the Rights to Legal Capacity in the United Nations Convention on the Rights of Persons with Disabilities: Responding to Major Concerns' (2015) 15(1) Human Rights Law Review 45, 46.

44 The burgeoning sub-discipline of 'legal capacity' scholarship has emerged in part through this debate: for example, Jill Stavert, 'The Exercise of Legal Capacity, Supported Decision-Making and Scotland's Mental Health and Incapacity Legislation: Working with Disability Convention Challenges' (2014) 4 Laws 296; Piers Gooding and Eilionóir Flynn, 'Querying the Call to Introduce Mental Capacity Testing to Mental Health Law: Does the Doctrine of Necessity Provide 
involving the provision of supports and accommodations to a person in their exercise of legal capacity, with their consent - such as by enabling them to make, and communicate their wishes and preferences about a decision which affects them. ${ }^{45}$

Scholars such as Bernadette McSherry, Kay Wilson, Penelope Weller, Linda Steele and Leanne Dowse have urged a broadening beyond a narrow focus on decision-making and legal capacity towards a more holistic view of the CRPD. ${ }^{46}$ A number of articles gathered in this special edition take up this challenge, opening up new territory in areas such as the accessibility of the criminal justice system, discrimination in the education system and the communication technologies that are vital to equal citizenship. The significance of Art 12 for domestic implementation of the CRPD nonetheless informs a number of the themes in this collection. The reception of Art 12 at a domestic level has been controversial largely because of states parties' concerns that it requires the abolition of substitute decision-making regimes, such as guardianship and involuntary detention and treatment pursuant to mental health laws. From the outset, a number of states parties (including Australia) entered Interpretive Declarations relating to Art 12 on ratification, to make clear their interpretation that substitute decision-making regimes do not breach the provisions of the CRPD ${ }^{47}$ In 2014, the UN Committee sought to provide some clarity on this matter, releasing its first-ever general comment on the CRPD dealing with Art 12 (General Comment No 1). ${ }^{48}$ The UN Committee's interpretation is that Art 12 makes it clear that "perceived or actual deficits in mental capacity must not be used as a justification for denying legal capacity', ${ }^{49}$ and does in fact require states parties to repeal laws providing for substitute decision-making and instead develop supported decision-making alternatives. ${ }^{50}$ This

an Alternative?' (2015) 4(2) Laws 245; Chris Ryan, Sascha Callaghan and Carmelle Peisah, 'The Capacity to Refuse Psychiatric Treatment: A Guide to the Law for Clinicians and Tribunal Members' (2015) 49(9) Australian and New Zealand Journal of Psychiatry 848.

45 Piers Gooding, 'Supported Decision-Making: A Rights-Based Disability Concept and its Implications for Mental Health Law' (2013) 20(3) Psychiatry, Psychology and Law 431, 434.

46 Bernadette McSherry and Kay Wilson, 'The Concept of Capacity in Australian Mental Health Law Reform: Going in the Wrong Direction?' (2014) 40 International Journal of Law and Psychiatry 60; Penelope Weller, "The Right to Health: The Convention on the Rights of Persons with Disabilities' (2010) 35(2) Alternative Law Journal 66; Linda Steele and Leanne Dowse, 'Gender, Disability Rights and Violence Against Medical Bodies' (2016) 31(88) Australian Feminist Studies 117.

47 For example, Australia, Ratification (with Declarations), registered with the Secretariat of the United Nations 17 July 2008, 2527 UNTS 289 (date of effect 16 August 2008).

48 General Comment No 1, above n 11.

49 Ibid [13].

50 Ibid [7], [17], [26]-[28], [50]. 
generalised guidance has frustrated some states parties ${ }^{51}$ and a number of commentators. ${ }^{52}$

In light of these tensions, those wishing to create law, policy and practice in conformity with the CRPD are continuing to debate what is meant by the notion of 'universal legal capacity' and particularly 'support ... in exercising ... legal capacity'. ${ }^{53}$ While commentators have expressed conflicting opinions on whether substitute decision-making is compatible with the CRPD ${ }^{54}$ an increasing number of them agree with the UN Committee's interpretation. ${ }^{55}$ In any case, uncertainty around the requirements of Art 12 and the significant ramifications it has for existing domestic laws have generated a wealth of scholarship in Australia and elsewhere which has sought to grapple with the associated issues of interpretation, obligation and implementation. ${ }^{56}$ As noted, the ALRC

$51 \quad$ For example, Denmark Ministry of Children, Gender Equality, Integration and Social Affairs, 'Response from the Government of Denmark with regards to Draft General Comment on Article 12 of the Convention - Equal Recognition before the Law' (2014) <http://www.ohchr.org/EN/HRBodies/CRPD/Pages/ DGCArticles12And9.aspx>; Republique Française, 'Commentaire de la France sur le project d'observations générales du Comité des droits des personnes handicapées, relatif à l'article 12 de la Convention relative aux droits des personnes handicapées' (2014) <http://www.ohchr.org/EN/HRBodies/CRPD/Pages/ DGCArticles12And9.aspx>.

52 For example, John Dawson, 'A Realistic Approach to Assessing Mental Health Laws' Compliance with the UN Disability Convention' (2015) 40 International Journal of Law and Psychiatry 70.

53 CRPD Art 12(3).

54 Some commentators express the view that substitute decision-making is permissible under the CRPD, but should only be considered where it has been established that the person cannot make the relevant decision with support measures: Gavin Davidson, Lisa Brophy, Jim Campbell, Susan J Farrell, Piers Gooding and Anne-Marie O'Brien, 'An International Comparison of Legal Frameworks for Supported and Substitute Decision-Making in Mental Health Services' (2016) 44 International Journal of Law and Psychiatry 30, 66; Dawson, above $\mathrm{n} 52$.

55 Fleur Beaupert and Linda Steele, 'Questioning Law's Capacity' (2015) 40 Alternative Law Journal 161; Eilionóir Flynn and Anna Arstein-Kerslake, 'The Support Model of Legal Capacity: Fact, Fiction, or Fantasy?' (2014) 32 Berkeley Journal of International Law 124; Leslie Salzman, 'Rethinking Guardianship (Again): Substituted Decision Making as a Violation of the Integration Mandate of Title II of the Americans With Disabilities Act' (2010) 81 University of Colorado Law Review 157; Bernadette McSherry, 'Mental Health Laws: Where to From Here?' (2014) 40 Monash University Law Review 175. Tina Minkowitz and Amita Dhanda were early pioneers of this approach: Tina Minkowitz, 'The United Nations Convention on the Rights of Persons with Disabilities and the Right to Be Free from Nonconsensual Psychiatric Interventions' (2007) 34 Syracuse Journal of International Law and Commerce 405; Amita Dhanda, 'Legal Capacity in the Disability Rights Convention: Stranglehold of the Past or Lodestar for the Future?' (2006-2007) 34 Syracuse Journal of International Law and Commerce 429.

56 The scholarship is too vast to provide a comprehensive list here. For a flavour of the diversity of this scholarship see, for example, Peter Bartlett, "The United Nations Convention on the Rights of Persons with Disabilities and Mental Health Law' (2017) 75(5) Modern Law Review 752; Sascha Callaghan and Christopher Ryan, 'An Evolving Revolution: Evaluating Australia's Compliance with the 
report on Equality, Capacity and Disability in Commonwealth Laws is one of few large-scale official inquiries to look in detail at Art 12 and its implications for domestic laws,${ }^{57}$ and directly address the competing views that have emerged in this respect. ${ }^{58}$ The special issue opens with a comment by Rosalind Croucher, Immediate Past President of the ALRC, about a central tenet of the Commission's approach in conducting this landmark inquiry - to confront the pejorative language that has been used in law and society to express disability and develop a new lexicon for the inquiry's reform proposals to signal the paradigm shift reflected in the CRPD.

Bruce Alston and Terry Carney, in their respective articles, consider how law and policy reform in guardianship and administration may facilitate wide-scale implementation of supported decision-making in domestic laws and practices, in addition to the challenges involved in this enterprise. Alston's article, drawing on the ALRC's work on the equality, capacity and disability inquiry, suggests that giving legislative effect to the National Decision-Making Principles recommended in the ALRC report is a pragmatic way to bring Australian laws closer to the CRPD's vision such that supported decision-making becomes the preferred response, while acknowledging that this approach may fall short of full compliance

Convention on the Rights of Persons with Disabilities in Mental Health Law' (2016) 39(2) University of New South Wales Law Journal 596; Tina Minkowitz, 'Rethinking Criminal Responsibility from a Critical Disability Perspective: The Abolition of Insanity/Incapacity Acquittals and Unfitness to Plead, and Beyond' (2014) 23(3) Griffith Law Review 434; Sascha Callaghan and Christopher Ryan, 'Is There a Future for Involuntary Treatment in Rights-based Mental Health Law?' (2014) 21(5) Psychiatry, Psychology and Law 747; Flynn and ArsteinKerslake, above n 55; Piers Gooding, 'Change and Continuity in Mental Health Law: The Long Road to the United Nations Convention on the Rights of Persons with Disabilities and its Implications for Mental Health and the Law Today' (2014) 20(3) Web European Journal of Current Legal Issues <http://webjcli.org/ article/view/367/470>; Trevor Ryan, Andrew Henderson and Wendy Bonython, "Voting with an "Unsound Mind"?: A Comparative Study of the Voting Rights of Persons with Mental Disabilities' (2016) 39(3) University of New South Wales Law Journal 1038; Steele, 'Court-Authorised Sterilisation and Human Rights', above n 11; Penelope Weller, 'Reconsidering Legal Capacity: Radical Critiques, Governmentality and Dividing Practice' (2014) 23(3) Griffith Law Review 498; Terry Carney and Fleur Beaupert, 'Public and Private Bricolage: Challenges Balancing Law, Services \& Civil Society in Advancing CRPD Supported DecisionMaking' (2013) 36(1) University of New South Wales Law Journal 175; Talia Epstein, 'Financial Management and the Rights of People with Disability: A Fine Balance' (2011) 34(3) University of New South Wales Law Journal 835.

57 Another country to engage directly with the challenges of the right to equal recognition before the law according to Art 12 of the CRPD is Ireland. The Assisted Decision-Making (Capacity) Bill 2015 (Ireland) was developed explicitly with the CRPD as the lead point of guidance for change. See Assisted Decision-Making (Capacity) Act 2015 (Ireland) (Act No 64).

58 In so doing, the ALRC clearly ventured into the realm of 'social law reform' that has increasingly characterised the work of Australian law reform bodies: see Marcia Neave, 'Law Reform and Social Justice' in Brian Opeskin and David Weisbrot (eds), The Promise of Law Reform (Federation Press, 2015) 358. 
with Art 12. Alston argues that replacing the 'best interests' model of traditional guardianship regimes with the 'will, preferences and rights' concept at the core of the National Decision-Making Principles - that the 'will, preferences and rights of persons who may require decision-making support must direct decisions that affect their lives' - has the potential to make a real difference in people's lives and will assist in advancing long-term cultural change. Carney assesses existing supported decisionmaking programs and trials for people with cognitive impairments, including the implementation strategies that may be needed to prevent supported decision-making becoming another vehicle for paternalistic and controlling interventions. He argues that these strategies must pay more attention to capacity building not only for people with disability but also their supporters, as an obligation arguably founded in the CRPD's socioeconomic right to support.

Piers Gooding et al examine how supported decision-making may be implemented specifically in the context of unfitness to stand trial laws, posing the difficult question whether such laws should be viewed as accessibility measures or a disabling barrier to the equal recognition of people with disability before the law. Starting from the assumption that the CRPD requires accommodations for people with disability to be integrated into the criminal justice system rather than the creation of separate legal processes that fail to secure due process rights, the authors consider the range of supports and accommodations that might assist an accused person with a cognitive disability to participate in a standard trial. They highlight the current lack of consistency in the approach taken by different courts and the need to expand on and formalise such support measures.

Evaluating unfitness to stand trial laws from a different perspective, Rhianna Chisholm, Tamara Tulich and Harry Blagg turn attention to the criminal justice system response to young people with Foetal Alcohol Spectrum Disorder (FASD), responding to specific concerns raised by Indigenous women in Fitzroy Crossing, Western Australia, about the susceptibility of Indigenous young people with FASD to contact with this system. Their article offers a critique of the social model of disability and disability neutrality as applied in this context, cautioning that these concepts may operate to deny the colonial underpinnings of disability in Indigenous communities. In suggesting a number of specific reforms to unfitness to stand trial laws, Chisholm, Tulich and Blagg argue for a response that facilitates Indigenous community-owned solutions and is sensitive to Indigenous culture, through reading the CRPD 'in tension' with the United Nations Declaration on the Rights of Indigenous Peoples ${ }^{59}$ which provides for collective Indigenous rights.

The articles by Karen O'Connell and Gerard Goggin explore ways in which people with disability are denied the right to participate equally

59 United Nations Declaration on the Rights of Indigenous Peoples, GA Res 61/295, UN GAOR, 61st sess, 107th plen mtg, Supp No 49, UN Doc A/RES/61/295 (13 September 2007). 
in particular aspects of public life, pointing to limitations of existing conceptualisations of disability discrimination. O'Connell asks how the CRPD's approach to defining disability - as 'co-created' by individual, environmental and institutional factors rather than a static individual attribute - might expand the approach taken by discrimination laws to students with challenging behaviours. On the current approach, lack of diagnosis can mean that students with challenging behaviours are denied much needed support in the school environment. While challenging behaviours are increasingly linked to a range of disabilities, O'Connell raises compelling questions about appropriate responses where such behaviours may instead be linked to trauma, poverty or social disadvantage. Through examination of case law, complaints data and interviews with professionals and advocates, she argues for a more contextual, systemic approach, taking into account the 'disabling' impact of institutions and sectors, and suggests that there may be a case for removing individualised definitions of disability from discrimination laws altogether.

Fundamental to effective participation in political and public life, in addition to cultural life, recreation, and countless daily activities, is effective access to information and to communications technologies and systems. Goggin traces the evolution of communication rights as part of international human rights and analyses how these rights have played out in Australia since the CRPD entered into force, noting the limited impact of the Convention to date. He demonstrates that disability perspectives on what is considered 'standard' communication necessitate a reimagining of communication rights, whereby they are positioned as pivotal to the broader human rights project. Article 21 of the CRPD on freedom of expression and opinion rearticulates this 'classic' right as one requiring the provision of information and services to the general public in accessible formats and technologies and the acceptance of diverse modes of communication, as chosen by and appropriate to people with different kinds of disabilities. Goggin argues for a broadened definition of communication rights and the development of a comprehensive national legal framework for their delivery, informed by the lived experience of disability. Both O'Connell and Goggin then suggest that the particular articulation of human rights in the CRPD not only holds promise for advancing the rights of people with disability but may also require us to rethink equal citizenship and supports for all people who may face barriers to civic participation and communication.

The CRPD has significant implications for existing domestic legal frameworks affecting the rights of people with disability. Yet, for the Convention to result in any change to these frameworks, Australian governments must make reforms to legal, political and social systems. As stated by Christof Heyns and Frans Viljoen over 10 years ago:

The success or failure of any international human rights system should be evaluated in accordance with its impact on human rights practices on the domestic or country level ... [R]atification in itself is largely a formal and in some cases an empty gesture. The challenge now is to ensure that the 
promises contained in the treaties and affirmed through ratification are realised in the lives of ordinary people around the world..$^{60}$

This special issue is a contribution to ongoing debates about disability justice that are taking place across academia, government, international and local organisations and civil society, specifically considering the challenges and opportunities associated with implementing international human rights obligations at the domestic level. We hope that this special issue opens up a space for discussion - it has by no means aspired to comprehensively address all of the disability rights issues confronting Australia. Areas not addressed in this special issue that warrant further consideration include civil mental health laws, refugee and migration law, employment law, international humanitarian law, legal issues affecting cultural life, law and policy of voting and political participation, housing, tenancy and social welfare law, legal issues pertaining to the intersection of disability, gender and ageing, the interaction between law and race/ ethnicity/cultural diversity, and the monitoring of sites of deprivation of liberty. To the ends of further research in this sphere, the authors in this collection pose questions and solutions which look beyond existing legal realities to legal possibilities that are necessarily informed by alternative ethical ideals and practices. As demonstrated by the articles that follow, law reform initiatives must think beyond the limits of existing domestic laws to imagine different and interconnected legal, social, cultural and political responses to disability.

60 Christof Heyns and Frans Viljoen, The Impact of the United Nations Human Rights Treaties on the Domestic Level (Kluwer Law International, 2002) 1. 